Portland State University

PDXScholar

TREC Final Reports

Transportation Research and Education Center

(TREC)

$4-2016$

\title{
Disseminating the Sustainable City Year Program (SCYP) Education Model
}

Nico Larco

University of Oregon

Marc Schlossberg

University of Oregon

Follow this and additional works at: https://pdxscholar.library.pdx.edu/trec_reports

Part of the Environmental Studies Commons, Transportation Commons, Transportation Engineering Commons, and the Urban Studies Commons

Let us know how access to this document benefits you.

\section{Recommended Citation}

Larco, Nico and Schlossberg, Marc. Disseminating the Sustainable City Year Program (SCYP) Education Model. NITC-TT-777. Portland, OR: Transportation Research and Education Center (TREC), 2016.

https://doi.org/10.15760/trec.126

This Report is brought to you for free and open access. It has been accepted for inclusion in TREC Final Reports by an authorized administrator of PDXScholar. Please contact us if we can make this document more accessible: pdxscholar@pdx.edu. 


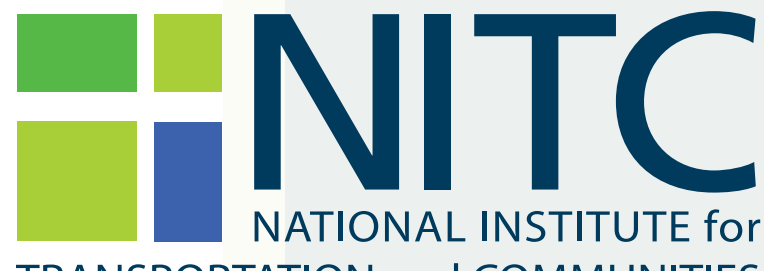

TRANSPORTATION and COMMUNITIES

FINAL REPORT

Disseminating the Sustainable City Year Program Education Model

NITC-TT-777 April 2016

NITC is the U.S. Department of Transportation's national university transportation center for livable communities.

HITEC 


\title{
DISSEMINATING THE SUSTAINABLE CITY YEAR PROGRAM EDUCATION MODEL
}

\author{
Final Report \\ NITC-TT-777 \\ by \\ Nico Larco \\ University of Oregon \\ Marc Schlossberg \\ University of Oregon
}

for

National Institute for Transportation and Communities (NITC)

P.O. Box 751

Portland, OR 97207
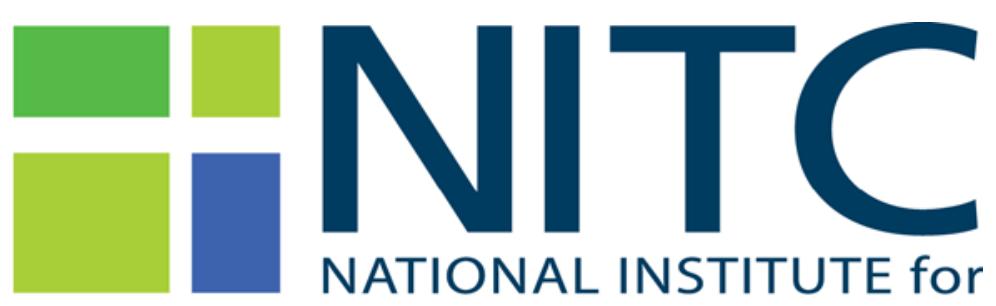

TRANSPORTATION and COMMUNITIES

April 2016 



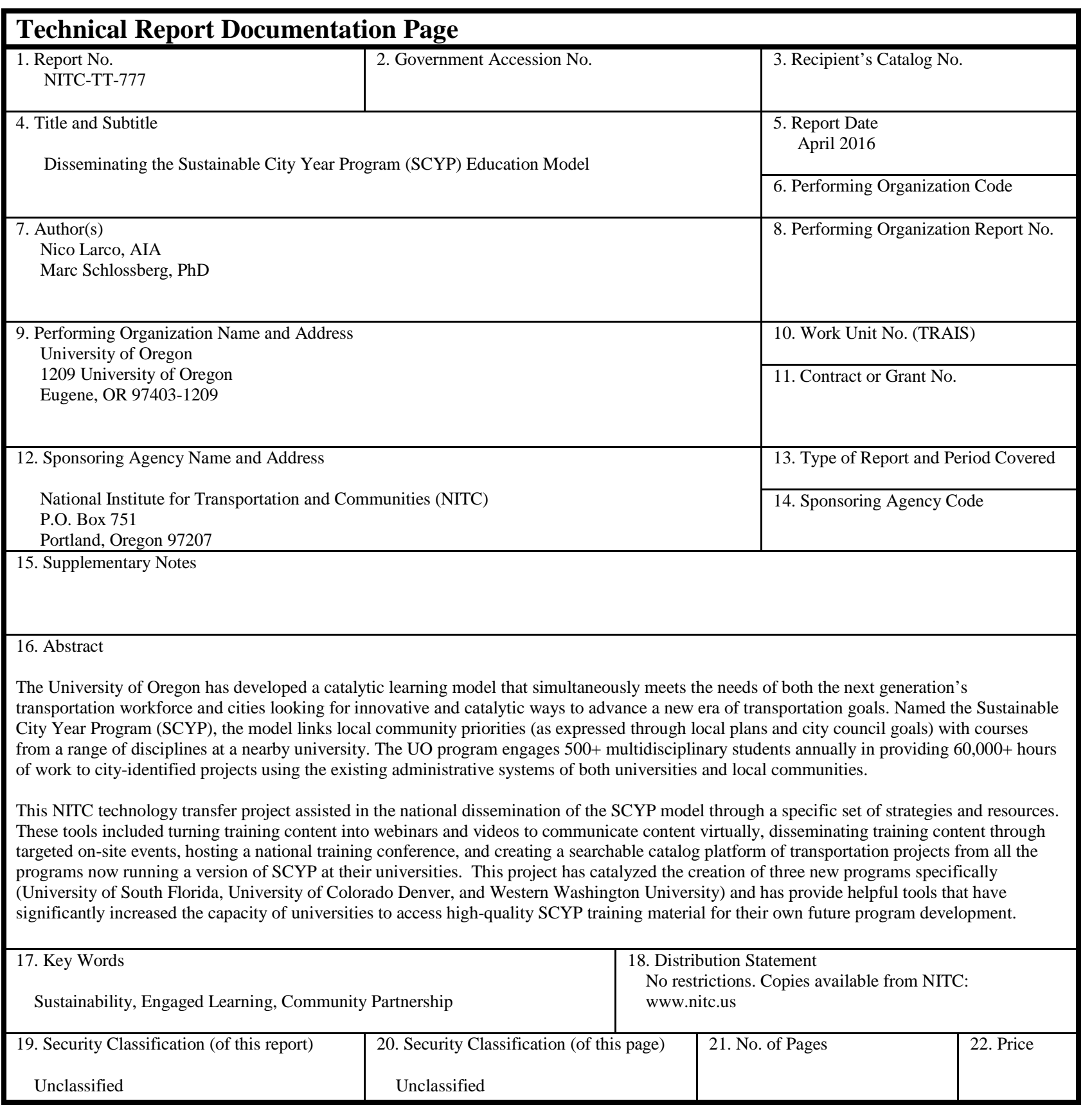





\section{ACKNOWLEDGEMENTS}

This project was funded by the National Institute for Transportation and Communities (NITC) and we are grateful for the support and encouragement to think about transportation in diverse and innovative ways. Many thanks to the Sustainable Cities Initiative (SCI) at the University of Oregon for their administrative support and platform upon which applied, cross-disciplinary work can proceed as though it was the norm within academia. We would also like to acknowledge the tremendous effort that Liz Rickles, graduate student in Public Administration, provided toward this project - her insight, organization, and leadership were amazing.

\section{DISCLAIMER}

The contents of this report reflect the views of the authors, who are solely responsible for the facts and the accuracy of the material and information presented herein. This document is disseminated under the sponsorship of the U.S. Department of Transportation University Transportation Centers Program in the interest of information exchange. The U.S. Government assumes no liability for the contents or use thereof. The contents do not necessarily reflect the official views of the U.S. Government. This report does not constitute a standard, specification, or regulation. 



\section{TABLE OF CONTENTS}

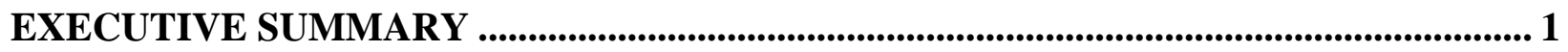

1.0 INTRODUCTION........................................................................................................ 2

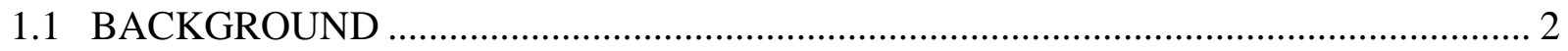

2.0 INTENTION, METHODOLOGY AND PROCESS ................................................. 5

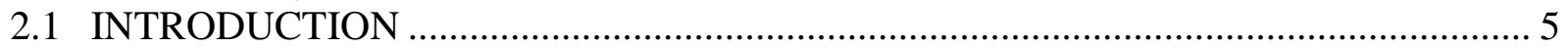

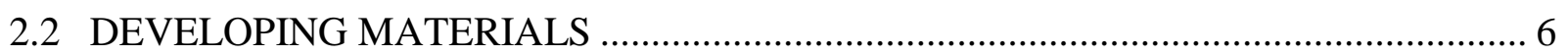

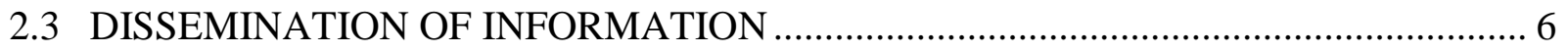

3.0 PROJECT DELIVERABLES .................................................................................. 7

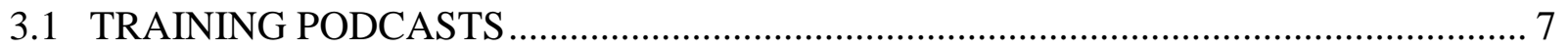

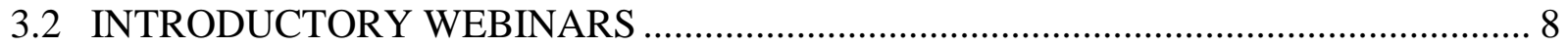

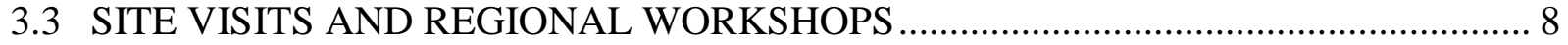

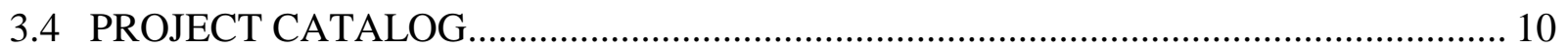

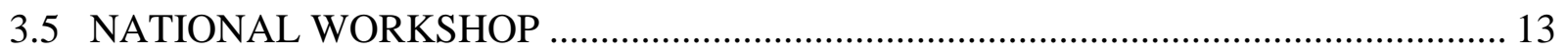

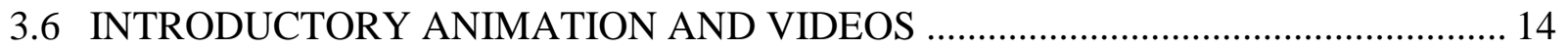

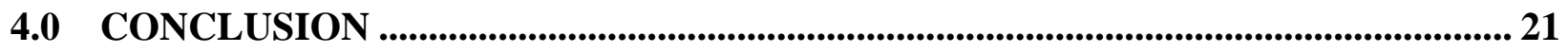

REFERENCES........................................................................................................ 23 



\section{EXECUTIVE SUMMARY}

The creation of livable communities requires contributions from a wide range of skillsets and academic disciplines. Even for projects focused on transportation, skills beyond transportation engineering and planning are necessary. The work of urban designers, policymakers, public administrators, GIS experts, economists, lawyers, businesses, community outreach specialists and more are needed to create livable communities that support safe and sustainable forms of transportation. To address this need, universities must step up to the challenge of training the next generation of the transportation workforce within all of these disciplines. At the same time, communities are desperately seeking assistance in all of these domains as they retrofit to meet shifting generational preferences for walkable, bikable and transit-friendly neighborhoods.

The University of Oregon has developed a catalytic learning model that simultaneously meets the needs of both the next generation's transportation workforce and cities that are in need of support to achieve their transportation goals. Named the Sustainable City Year Program (SCYP), the model links local community priorities (as expressed through local plans and city council goals) with courses from a range of disciplines at a nearby university. The UO program engages $500+$ multidisciplinary students annually in providing 60,000+ hours of work to city-identified projects using the existing administrative systems of both universities and local communities.

This NITC technology transfer project assisted in the national dissemination of the SCYP model through a specific set of strategies and resources. These tools included turning training content into webinars and videos to communicate content virtually, disseminating training content through targeted on-site events, hosting a national training conference, and creating a searchable catalog of SCYP transportation projects. These tools have directly empowered at least three universities to begin the process of implementing a SCYP program, have provided tools and resources for the 20+ universities now implementing an adaptation of SCYP, and have significantly increased the capacity of other universities to access high-quality SCYP training material in the future. 


\subsection{INTRODUCTION}

\subsection{BACKGROUND}

Traditional classroom learning can serve many students and subjects well. In the traditional approach, the core educational experiences of most students happen on campus within a lecture or lab format.

For highly technical or theoretical fields, this approach may be entirely adequate. But for many future professionals who work with public issues, this traditional approach is limiting. Today, professionals are expected to know how to work across disciplines, collaborate in teams, understand local community politics, publicly present their work orally and in writing, and possess a host of other "soft" skills that are critically important in today's workforce. While some of these skills can be taught and practiced in a traditional classroom, many cannot, and many students seek out applied learning opportunities as part of their education (Weinstein, Agrawa and Dill, 2008).

One approach to expanding this skill set is through applied or experiential learning opportunities. Experiential learning encourages the development of transferable professional skills, such as working in collaborative teams, developing public communications skills, and creative problem solving. Learning of this kind can result in a more rewarding educational experience for students (Kotval, 2003). In these settings, students work on real-world projects in conjunction with realworld partners. Student work is both grounded in actual professional situations and accountable to an outside audience who provides professional input and critique to students as they learn. Additionally, some argue that, more than just providing richer educational experiences for students, universities should also support service learning to help provide desperately needed assistance to local communities or agencies (Checkoway, 1997).

Despite the benefits, there are a variety of factors that prevent more university courses from including public engagement components. Many instructors have not been trained in or exposed to such pedagogy and do not understand how to lead this type of content, or are simply unaware of its benefits. Moreover, many instructors may be hesitant to develop community-engaged courses because of the time commitment required from students and community partners.

Given these challenges, developing opportunities for instructors to connect easily to community engagement options, without their needing to be the lead champion for such projects, may be a key for engaging more faculty and students in applied, experiential opportunities as part of their education.

Additionally, while communities may have needs that could benefit from university engagement, it is often difficult for them to know how to access a university's resources. In many communities, previous faculty and student engagement has caused more harm than good. Thus, a model is needed that emphasizes community-initiated, community-driven, and jointly community-led projects to ensure that benefits accrue to all participants. 
This is the backbone of the Sustainable City Year Program (SCYP) structure. SCYP uses the existing administrative systems of both universities and local communities, but harnesses their resources in a new way. At the University of Oregon, each year SCYP matches 25-35 courses across 12 disciplines to the transportation and sustainability challenges of a different city. The program engages $500+$ students annually who provide $60,000+$ hours to city-identified projects. While many universities engage in applied or service-based learning, none do it at this scale. This scale has a significant impact on participating students, faculty, institutions and the community partner.

The U.S. Department of Transportation's (USDOT) livability initiatives aim to develop transportation options so that not every trip must be made by car, and so that livability is incorporated with the larger community design. Policies should support appropriate land uses, street connectivity, community engagement and smart development to achieve a maximum amount of transportation and housing choices while facilitating an improved community quality of life. SCYP addresses all of these elements by linking local community priorities, as expressed through local plans and city council goals, with courses at a nearby university from a range of disciplines. In the Oregon version of SCYP, for example, students worked on transportation and livability projects identified by city leadership in city planning, law, architecture, landscape architecture, business, journalism, product design, economics, public administration, geography, and even arts administration. Courses in civil engineering from a nearby university have also been incorporated into this very open and flexible model. There likely is no other program in the nation addressing transportation and livability issues as comprehensively as SCYP.

In 2012, SCYP began training other universities on launching and running the model. As of this report, there are adapted programs running at a variety of university types in 13 states. This NITC project expanded that training and added some transportation-specific elements to help universities expand their ability to address real-world transportation issues that local communities face. SCYP was a featured element in the Transportation Research Board's 2012 special conference and report on workforce development within the transportation field, and the featured topic at an annual gathering of University Transportation Center directors in January 2014. There was subsequently a high degree of enthusiasm and demand for training on the SCYP model, and this NITC project helped address that interest. By building a system of SCYP training materials, this project helped empower universities to improve undergraduate and graduate transportation and sustainability education while providing tangible benefits to city livability, safety and environmental sustainability across the country. 



\subsection{INTENTION, METHODOLOGY AND PROCESS}

\subsection{INTRODUCTION}

Demand for information about implementing the SCYP model has grown, and Sustainable Cities Initiative (SCI) has had difficulty keeping up with this demand. In April 2012, in response to repeated inquiries from across the country, SCI hosted a national training workshop that was attended by 35 representatives from 20 universities interested in replicating the SCYP model. Due to continuing interest, second-, third- and fourth-annual replication workshops have been held each April. Over 200 individuals have attended these workshops, in addition to representatives from the national Environmental Protection Agency (EPA) and from EPA Regions 5, 9 and 10. Adaptations of SCYP are now being implemented at the University of Minnesota, University of Iowa, San Diego State, Pennsylvania State, University of St. Thomas, University of Texas at Austin, Texas A\&M, University of Tennessee, University of Maryland, Augustana College, the University of Connecticut, Utah State, Arizona State, University of Colorado Denver, University of South Florida, University of Maryland, Western Washington University, Cal State Monterrey Bay, and more. Several programs are preparing to launch in the fall of 2016, including the University of Wisconsin, Chico State, Cal State East Bay, Sonoma State, and possibly the University of Washington, among others. Technion Institute of Technology in Israel also launched a program during the 2015-16 academic year.

Since 2012, SCYP has been developing the expertise and the content to help other institutions get up and running in ways that fit their institutional and community contexts, but such training had not yet been transformed into a format that could be reached by a much broader audience. This NITC grant provided assistance to deliver additional training on the program and ensure that new adoptions are organized for success.

This project aimed to expand the technology transfer work of disseminating the SCYP model to additional universities and communities. Specifically, the additional training support included:

1. Turning training content into webinars, videos, animations and audio podcasts to communicate content virtually;

2. Disseminating training content through regional on-site events or working directly on-site with specific universities deemed most ready to adopt and adapt this model for their institution;

3. Hosting a 2015 and 2016 national training conference and workshop with extra outreach to universities with robust transportation programs; and

4. Creating the infrastructure for a searchable catalog of successful applied-learning transportation projects from multiple disciplines and universities already adopting the SCYP program. 


\subsection{DEVELOPING MATERIALS}

Much like the collaborative nature of the SCYP model, the process of developing these training materials was truly a team effort. University of Oregon professors from two distinct disciplines Community and Regional Planning and Architecture - headed the project. In addition, universities across the country that have adapted SCYP for their context were enthusiastic about sharing their experiences with others so that more universities and communities can enjoy the benefits of the SCYP model. This group of universities is committed to giving students an applied educational experience that has opportunities to also advance local community goals. Staff at over a dozen universities contributed ideas on important training content, submitted projects for the database, and went on site visits to share their experiences.

The project also partnered with staff and students from the University of Oregon School of Journalism and Communication, who helped record the training podcasts, videos and animations. University of Oregon's CASIT program, which provides information technology services, also supported the creation of the online project database.

\subsection{DISSEMINATION OF INFORMATION}

The training podcasts, videos and project database are available on the SCI website. A separate, dedicated section of the website was created to present materials for universities interested in adapting the SCYP model (epicn.uoregon.edu).

Information about the training materials has been and will continue to be shared in SCI's social media and email listservs, through its annual conference, and through its national partners such as USDOT, EPA and others. The explanatory animation is being co-branded with individual programs at other universities to further dissemination and support of this model across the country. 


\subsection{PROJECT DELIVERABLES}

\subsection{TRAINING PODCASTS}

SCYP developed the key topics of the national workshop into smaller training modules that are now available online. The audio format delivers this informative content especially well. Unlike a webinar, which typically requires a 30- to 60-minute time commitment, the podcasts allow the user to select the topic they wish to hear more about and receive a concise answer in a fiveminute segment (or to hear the entire series in under an hour). The structure of these podcasts are such that as new needs develop from potential programs across the country, new customized podcasts can be created.

The topics covered in this initial podcast series include:

- What is the SCYP program?

- How are transportation projects implemented across the academy?

- What does the yearly SCYP schedule look like?

- How is the SCYP program funded?

- What does a transportation project look like from the professor's perspective?

- How do you find the first city partner?

- How does the SCYP model work from the city's perspective?

- What value does SCYP offer to cities?

- What value does SCYP offer to students?

- What value does SCYP offer to faculty?

- What value does SCCYP offer to university administration?

These episodes cover all of the most frequently asked questions about the SCYP program, as experienced by SCI over the past five years and by the network of schools currently running the model, and are targeted towards universities with transportation programs. Over time, more episodes on new topics can easily be created and shared. 


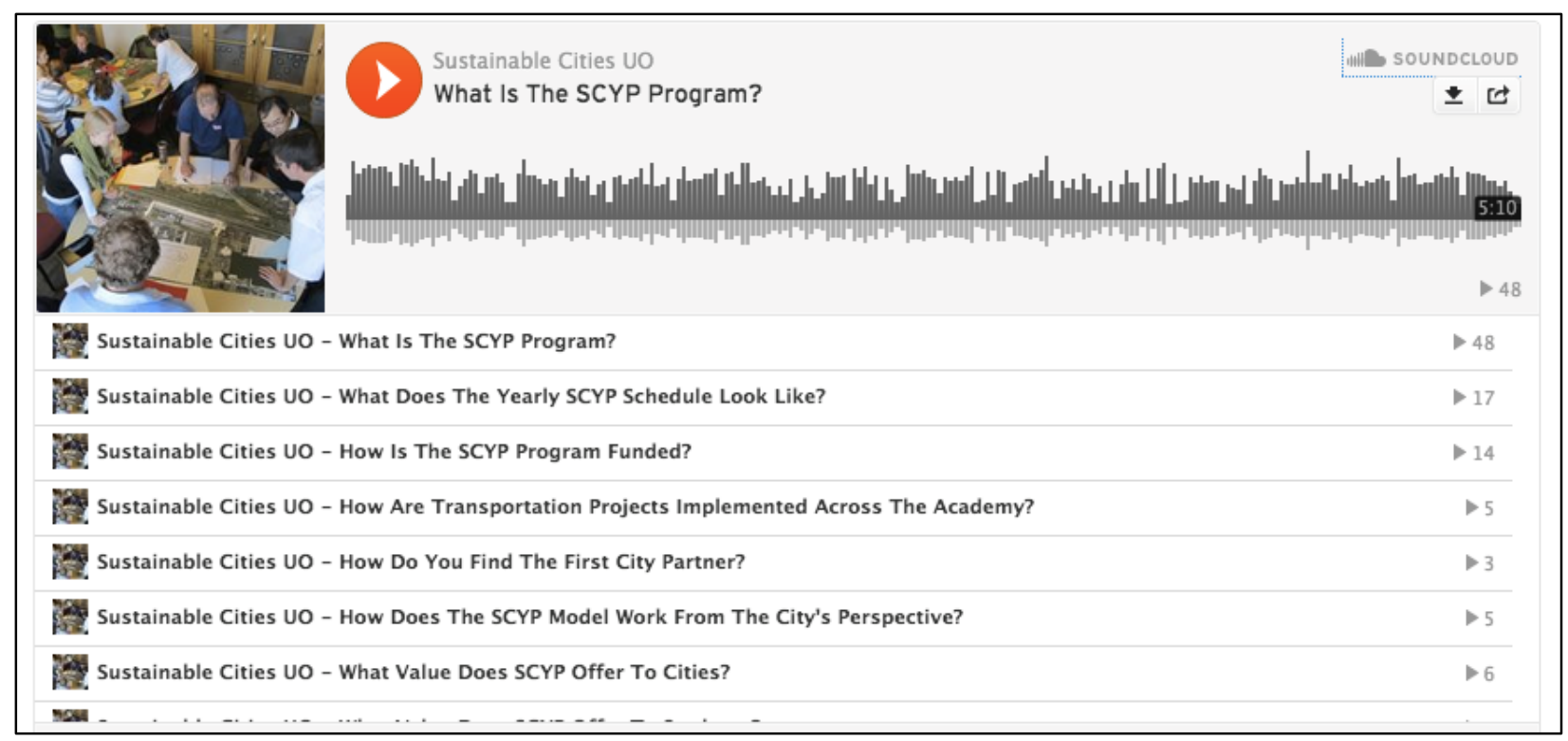

Figure 1: Screenshot of SCYP podcasts

\subsection{INTRODUCTORY WEBINARS}

SCYP presented two webinars that introduced new transportation-focused audiences to the SCYP model. The first webinar was held October 2, 2014, and was hosted by the University of South Florida's Center for Urban Transportation Research (CUTR). Over 30 participants viewed the webinar live. The 45-minute presentation provided details on the catalytic learning model, explained how it functions, and laid out how universities and communities can work together in new ways to meet our changing transportation challenges. The webinar was recorded and is now publicly available for viewing on CUTR's website.

A second webinar was held February 4, 2015. This webinar also targeted individuals in the transportation sector by promotion on listservs and social media, and through customizing content toward transportation-specific issues. Over 50 people registered for this event. This webinar was also recorded and is now publicly available on SCI's website.

\subsection{SITE VISITS AND REGIONAL WORKSHOPS}

The goal of site visits and regional workshops is to train additional universities and communities across the country to adopt and adapt the SCYP educational model. SCYP has found that on-site training is a very effective way to bring various constituent groups together to understand and prepare to adopt the SCYP model.

Professor Marc Schlossberg from SCI traveled to the University of South Florida for a site visit in February 2015. The site visit was hosted by USF's CUTR program, which is part of the national UTC effort, and USF has also become a member of NITC. The visit included presentations and meetings with faculty and university administrators as well as meetings with representatives from three potential partner cities. The meetings with potential partner cities allowed for city officials to gain an in-depth understanding of the model, ask questions and build excitement. The visit enabled USF to take their interest in SCYP to the next level and begin 
holding higher-level discussions about implementation and next steps. The entire process was facilitated by SCYP staff, making it more efficient and understandable for the involved stakeholders. Following the site visit, USF decided to send staff to the annual SCYP workshop and conference, and USF subsequently organized to launch a program of its own.

The USF site visit was also a valuable opportunity for collaboration and "training the trainer." Jessica Barlow, director of San Diego State’s adaptation of SCYP (The Sage Project), also attended the USF site visit and was able to bring a valuable perspective. Jessica launched the SCYP model at SDSU two years ago following a site visit from SCI, and she was able to share her experiences replicating the model with the USF team. The visit also allowed Professor Schlossberg to train Professor Barlow on leading an SCYP site visit. Professor Barlow has subsequently been able to conduct site visits to prospective university programs in Arizona and Indiana, and has guided conversations with several schools in California. Providing this "training the trainer" opportunity has greatly expanded the capacity for disseminating the model further.

In February 2015, Architecture Professor and SCI Co-Director Nico Larco traveled for a site visit to the University of Colorado Denver, which has a Transportation Engineering program and is a sub-grantee of the North Dakota State University UTC. In addition to giving a public presentation to a full auditorium, he met with CU Denver administrative leaders and professors. The convening of multiple stakeholders and staff at CU Denver built momentum and enabled the school to quick-start its program. Denver launched shortly thereafter, offering its first SCYP courses in the 2015-2016 academic year. CU Denver also sent two university representatives to the SCYP national training workshop, and these staff have become active contributors to a new national network of SCYP programs, further working to disseminate program knowledge widely. By providing the direct support that CU Denver needed to launch, this project expanded the conversation on how transportation is discussed and studied in higher education.

Professor Schlossberg from SCI also visited Western Washington University and the University of Washington in separate site visits. At both institutions, he convened university administrators, faculty and students in a series of conversations about SCYP. The visit allowed for Western Washington staff and faculty to gain an understanding of how transportation-focused projects can be implemented across their university in a variety of departments. These site visits were critical in developing the understanding of the model that motivated Western Washington University to send representatives to the annual conference and workshop in 2015, and the University of Washington to send representatives in 2016. A program at Western Washington will launch in the fall of 2016, and the University of Washington is organizing to launch in the fall of 2016 or 2017.

As this dissemination work unfolded, it became clear that there was an opportunity for the collection of universities running a version of SCYP to gather and co-develop strategies and content to catalyze the development of new programs, and to improve the programs already running. An initial gathering of such programs was held in November 2014 and a second inperson gathering was held in November 2015. SCYP organized the meeting to discuss new ways to engage more universities in the SCYP model, and to collaborate on the creation of the training resources that were being funded by this grant. Representatives from several universities were present and, collectively, the institutions decided to name this university-community partnership 
model the "Educational Partnership for Innovation in Communities (EPIC)” model; develop 12 key tenets that distinguishes this approach from other efforts; and do work to establish the EPICN (network) as a way to build on this NITC grant to create a mechanism to disseminate the model, translate knowledge to practice, educate the next generation workforce, and help cities implement new approaches to sustainable and livable community development.

\subsection{PROJECT CATALOG}

Along with many of the EPICN partners, SCYP has developed a project database designed to collect all of the class-based work from all of the EPICN programs around the country. The intent is to make the student output, faculty syllabi and EPICN program information publicly accessible to universities, faculty, students and communities, such that the adoption and implementation of everything from the model in general to the design of a particular class becomes easier to do.

Faculty and administrators who are interested in integrating transportation-focused, applied learning courses into their work can use this easily accessible, online project catalog for inspiration, project guidelines, and access to specific syllabi from other faculty across disciplines who have integrated applied transportation and other projects into their curriculum. This comprehensive catalog will allow project searches by academic department, student level, class size, city, school and more. It will include final reports by students and details about the teaching objectives of the course. This database will allow transportation-focused universities to receive inspiration and project guidelines for integrating SCYP into their own institutions.

The database is organized into several sub-sections:

- University - information in this section refers to broad qualities of the university and of the specific SCYP-styled program and includes data such as:

o School name

o Program name and website

o Year program began

o Type of academic schedule (quarters, semesters, both)

o University size

o Program name, logo, website, staffing, funding sources, and institutional location

- $\quad$ Partner - this is information about the community partner and includes data on:

o Name; type (municipality, transit district, MPO, etc.); jurisdiction population; distance from campus; contact information; dollar amount of contract; and relevant partnership files

- Project - this includes information about the specific project that a class and city partner are working on (i.e., street retrofit, urban redevelopment, community engagement, etc.) and includes data on:

o Project name and description; number of community members engaged; and project outputs (i.e., reports, videos, posters, key images, etc.)

- Instructor - this is information about each instructor that participates in a universitybased SCYP/EPIC program and includes: 
o Name and contact information, discipline, and main field of research

- $\quad$ Class - this is information about the specific class that participated in one of the programs and includes data on:

o Class title and number; academic level of students; instructor name(s); syllabi; enrollment information (student numbers, term and year); and key output documents (final synthesized course report, key images, etc.)

All sections also include open-ended, text-based fields and opportunities for multiple file uploads that can be used as needed.

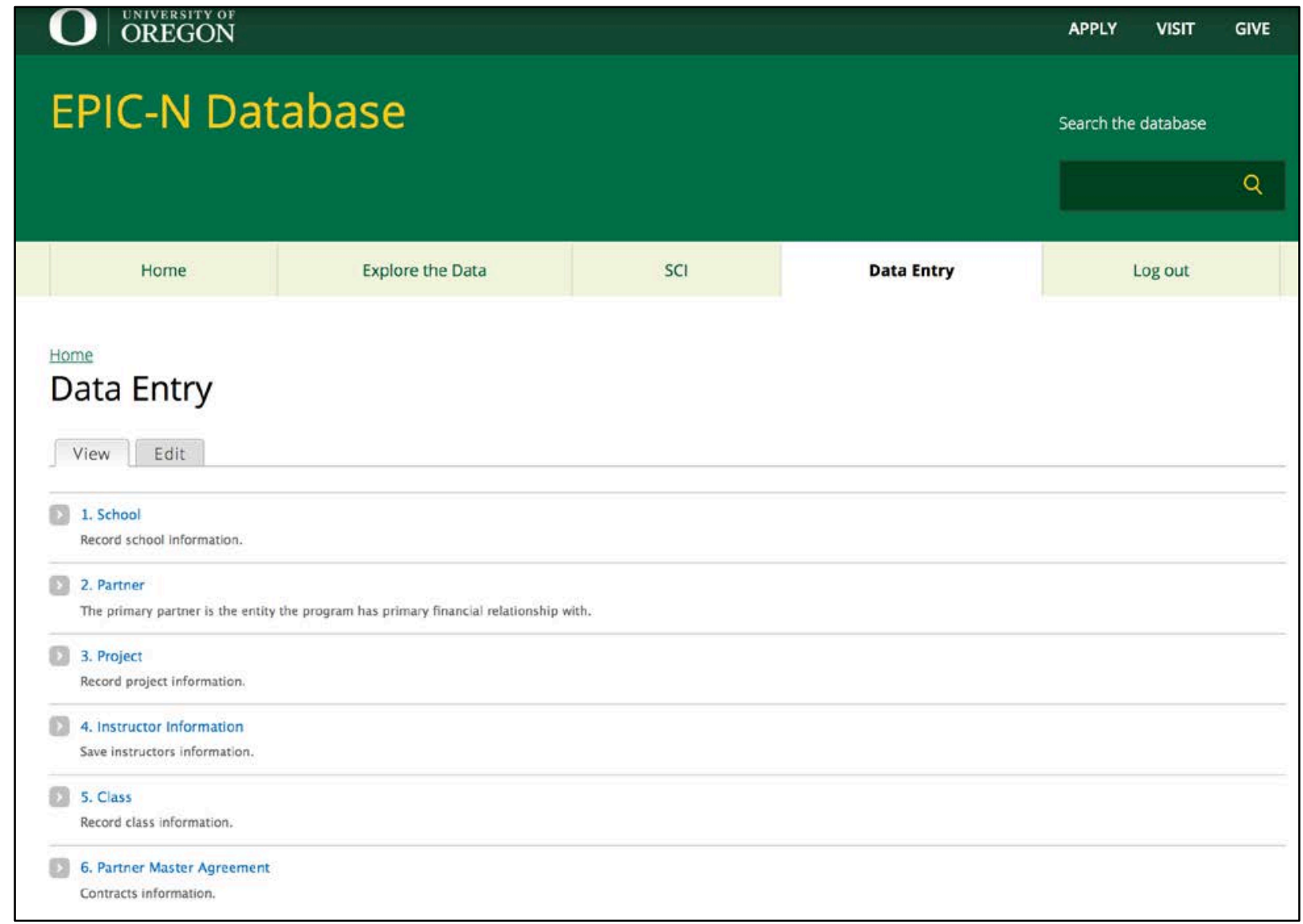

Figure 2: General Data Entry Portal for Program Managers 


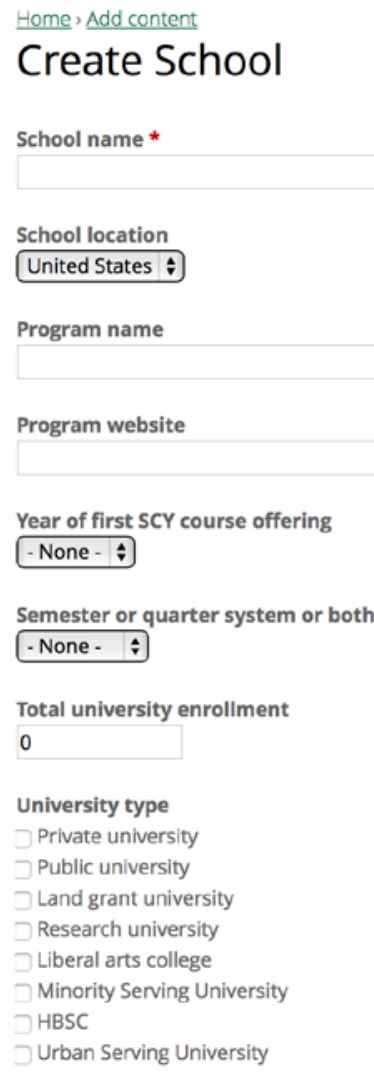

Figure 3 : Some Data Entry Fields for School /University

The database was finalized and beta tested at the end of this grant, and presented to attendees of the 2016 SCYP / EPICN annual conference and workshop. The University of Oregon has begun back-entering project data from its six years of operations into the database, and we anticipate that other programs will begin actively using the database for current operations and backentering data through the summer of 2016, with a useful collection of national data publicly available by fall 2016.

As data entry progresses, several options for database searching will be available, including:

- General database search through a "Google-styled" open search;

- A short list of pre-created or limited-option searches based on what we anticipate will be typical searches; and

- An option for a fully customizable search based on all fields in the relationship database. 


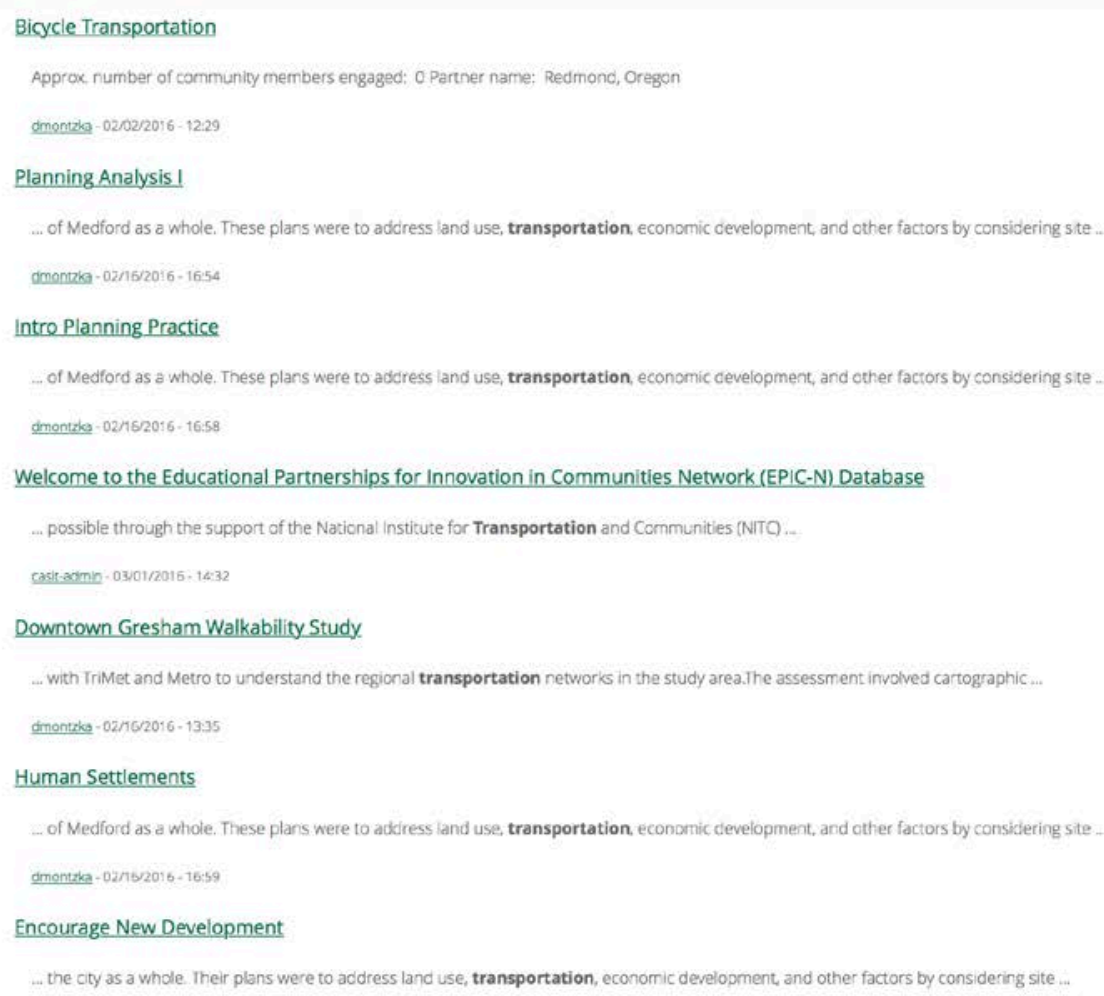

The database can be accessed through epicn.uoregon.edu.

\subsection{NATIONAL WORKSHOP}

SCYP held its fourth annual workshop in April 2015 and fifth workshop in March 2016. While NITC did not fund the workshops, the events supported the grant's goal of sharing the model with new universities and inspiring transportation projects across the academy. Many of the materials created through this NITC grant were disseminated at these workshops. Representatives from universities that had received site visits attended the workshops, which allowed for further conversation and more advanced training. Overall, the workshops were tools to leverage the work of this NITC grant.

The 2015 workshop was hosted by the Resilient Communities Project at the University of Minnesota, an SCYP program that launched after gaining the skills needed to implement the program at the first replication workshop in 2012. The 2015 workshop had nearly 60 attendees from around the United States. The 2016 workshop was hosted by San Diego State University's Sage Project, which formed in 2013 after site visits and conference attendance. The 2016 workshop also had nearly 70 attendees from around the United States, as well as representatives from a university in Israel (Technion) and China (Tsinghua), and was attended by several members of the EPA from Washington D.C. and Region 9 in California.

The workshop is targeted towards university representatives and city officials who are interested in bringing the SCYP model to their own communities. Each year, sessions include the nuts and 
bolts of operating an SCYP program, views from previous cities that have participated in the partnership, and the logistics of the pilot year, among other topics. Training sessions used transportation projects as examples.

The workshop also offered targeted sessions for universities who are already running SCYP programs. These capacity-building sessions were presented by faculty and staff from SCYP programs around the country. These sessions focused on program evaluation, communicating projects to key audiences, and working successfully with stakeholders, among other topics.

\subsection{INTRODUCTORY ANIMATION AND VIDEOS}

A key SCYP training element involves helping people reach what SCI calls the “aha!” moment that moment when the listener understands why cities and universities have significant incentives to buy in to the model, and understands how the program is financially sustainable.

SCI has created three significant videos to help communicate the uniqueness of the SCYP / EPIC model:

1. Animation explaining the keys to the university-community partnership;

2. Video describing the model and how multiple disciplines have addressed transportation and livability; and

3. Video explaining the " 12 Key Tenets" that makes this model unique, highly replicable, and institutionally sustainable.

\section{$\underline{\text { Animation }}$}

To describe the basic rationale and structure of how the SCYP (or EPICN) model works, we created an animation that explains the partnership in a generic format (not linked to the University of Oregon), but covering the basic structure that we have found leads to quick "aha" moments. This two-and-a-half-minute animation covers the challenges cities are facing; the strengths of students and universities in matching those challenges; the academic disciplines that can be brought to bear; and the key organizational structures that make this massively scaled partnership successful. The animation is concise and visually engaging, and has already been used at a variety of locations, from site visits to international conferences. In addition, the animation will be co-branded for each program running the SCYP model so that they can use it as they seek future community partners and continue to engage a broader cross section of faculty and disciplines across their campus. 

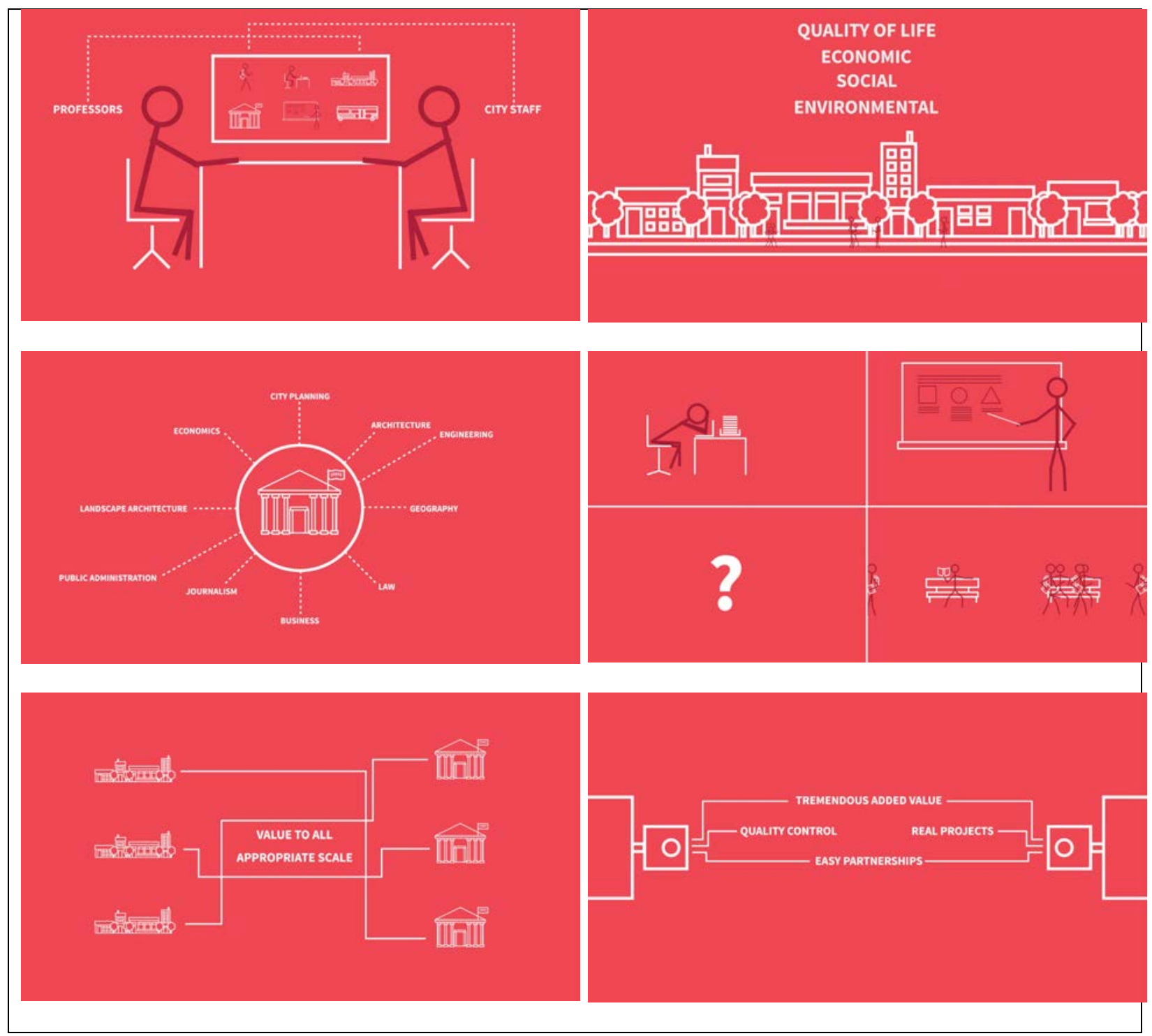

Figure 5: Screenshots from an animation describing the SCYP university-community partnership model

\section{$\underline{\text { Transportation Video }}$}

The "Transportation Across the Academy" video has two key components: 1) setting up the rationale as to why creating sustainable and livable transportation systems requires complex and diverse perspectives; and 2) how actual university courses across the academy can be engaged in such transportation work, even though the courses and students are not primarily focused on transportation studies. This video explores how issues of sustainable transportation can easily tap into the expertise of students and faculty in multiple majors not normally thought of as having much to do with transportation, but creating community value and exposing a more diverse student body to potential opportunities within the transportation workforce. 

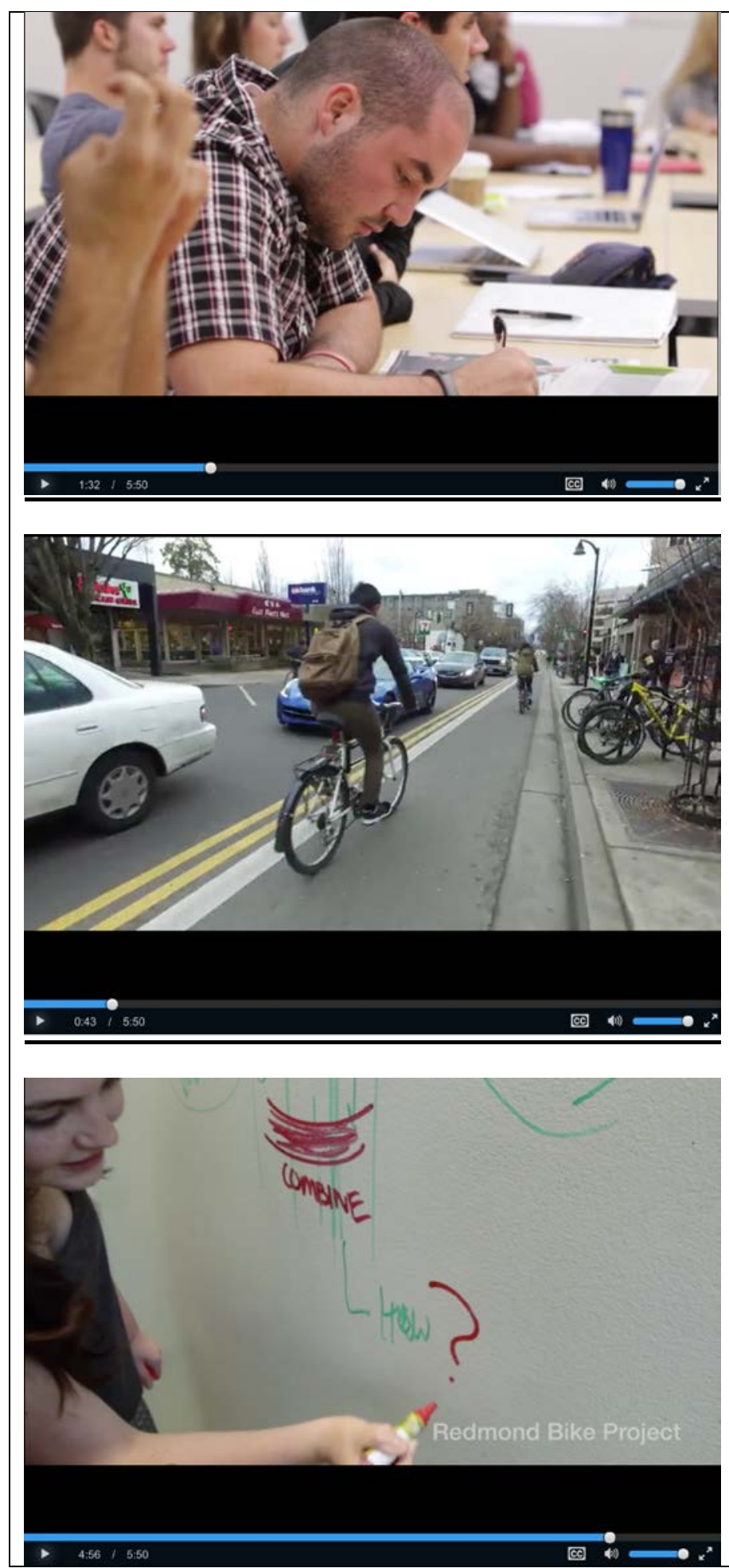

Figure 6: Screenshots from the "Transportation Across the Academy" Video

\section{Key Tenets Video}

There are many examples of formal university-community partnership programs, and even more examples of individual faculty teaching courses that include an applied, community-based 
project component. Through a deliberative process among several institutions running "the Oregon Model,” we were able to determine that there are 12 aspects of the model that are being implemented simultaneously that makes this framework distinct from any other universitycommunity partnership approach across the country. While these tenets are not unique to transportation-related projects, they do help articulate the simultaneous features of this engagement model that has led it to be so successful for communities, universities and students alike, and has proven to be easily replicable across institutional and community type.

The 12 Key Tenets of the EPIC Framework include:

1 This is a university and community partnership - Projects are identified by the community and only go forward after an iterative process between key community stakeholders and faculty where they jointly agree to a scope of work that satisfies both community and educational needs. Thus, this model is done with communities as full partners.

2 The program utilizes existing courses - On the university side, the program is largely based on courses that already exist, taught by instructors already scheduled to teach those classes, and assignments or course projects already part of the course structure.

3 The program is scaled for impact - The partnership must be at a sufficient scale of activity that its presence is felt in the community and on campus, in both quantity and across disciplines.

4 It is based on faculty opting in - Participation by faculty is voluntary and participating one year does not commit anyone to a subsequent year (although most faculty choose to remain involved). Frequently, participating in the program makes teaching applied courses actually easier, as there is a coordinator finding projects, bringing partners to the table, and organizing logistics. This is a ultimately a bottom-up process within the university.

5 Community partners are chosen through a deliberative selection process -EPIC is not exclusively focused on the host city of the university, and facilitates academic institutions to serve a broader geographical region and diverse set of communities, cities, metropolitan regions, or rural areas. Becoming a community partner is a competitive process for which a deliberative selection process ensures commitment and readiness.

6 Projects are defined by university and community consensus - Project ideas are finalized through an iterative match-making process between faculty and local government (or private sector or nonprofit) staff where ideas are jointly proposed and only those that meet each other's needs go forward.

7 There is a purposeful advancing of the social good as a core principal in this model These partnerships have a social agenda and address important societal issues such as sustainability, public health, social equity, economic development, general community quality of life or other pressing issues of concern appropriate to the municipality's needs and university’s capacity. 
8 Students are actively engaged in the endeavor - This is a program that taps students at a massive scale, in their courses, to provide insight, ideas and political space for local decision-making.

9 The program is multidisciplinary in approach - EPIC is a multicourse, multidiscipline approach toward learning and catalyzing community change. The scale allows a broader engagement of community stakeholders and decision makers, and creates buzz on and off campus in ways that are often not possible with single, isolated course approaches.

10 There is a defined geographic focus - The key to an EPIC program is that it harnesses multiple courses across campus and directs them to a single, geographically defined place, whether that is an entire small- to medium-sized city, a smaller subsection of a large city, key transit corridors, a port, or a Native American reservation.

11 There is a defined time limit to the partnership - The partnership ends, typically after one or two years and then another university partner is engaged. Because projects have to be part of existing municipal work plans, the work generated during the partnership continues to help guide community decision-making after the formal partnership ends.

12 There is a mutual investment by the city and university - Cities that participate must have financial "skin in the game" to ensure professional engagement, quality products and a coordinated approach.

The video covers these tenets and provides some context within which a viewer can understand them.

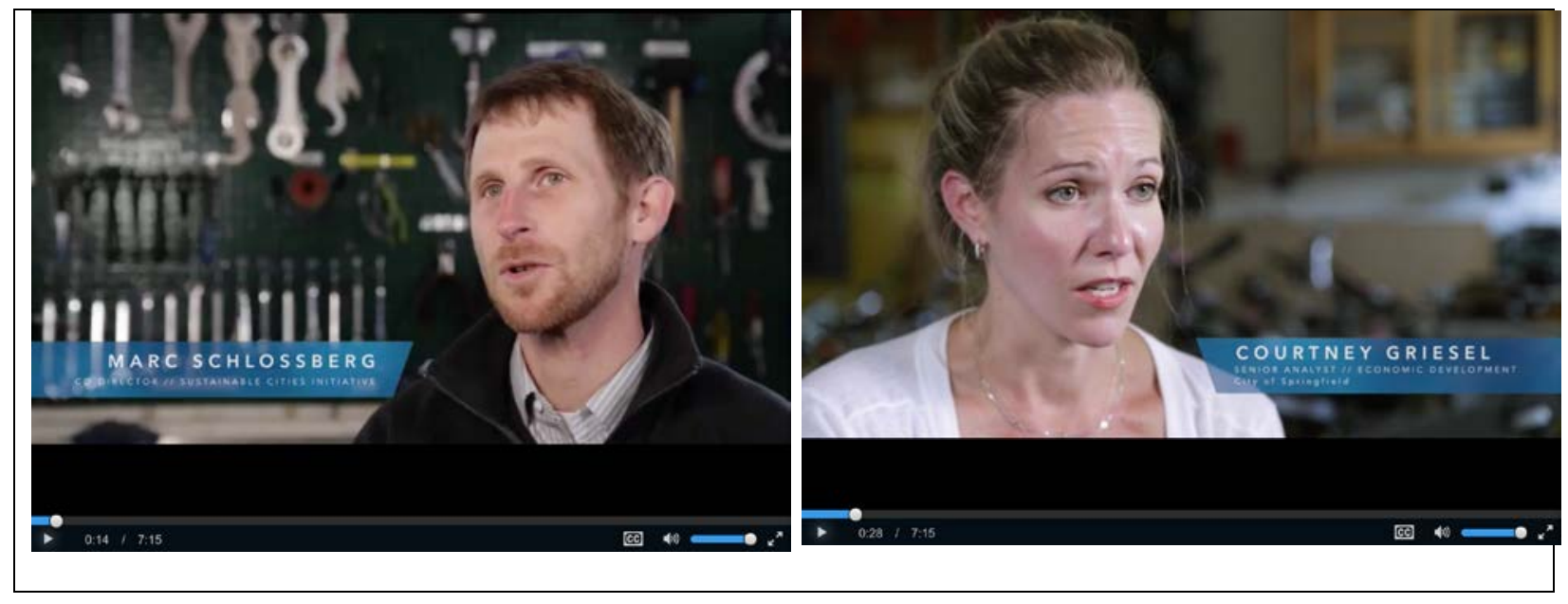




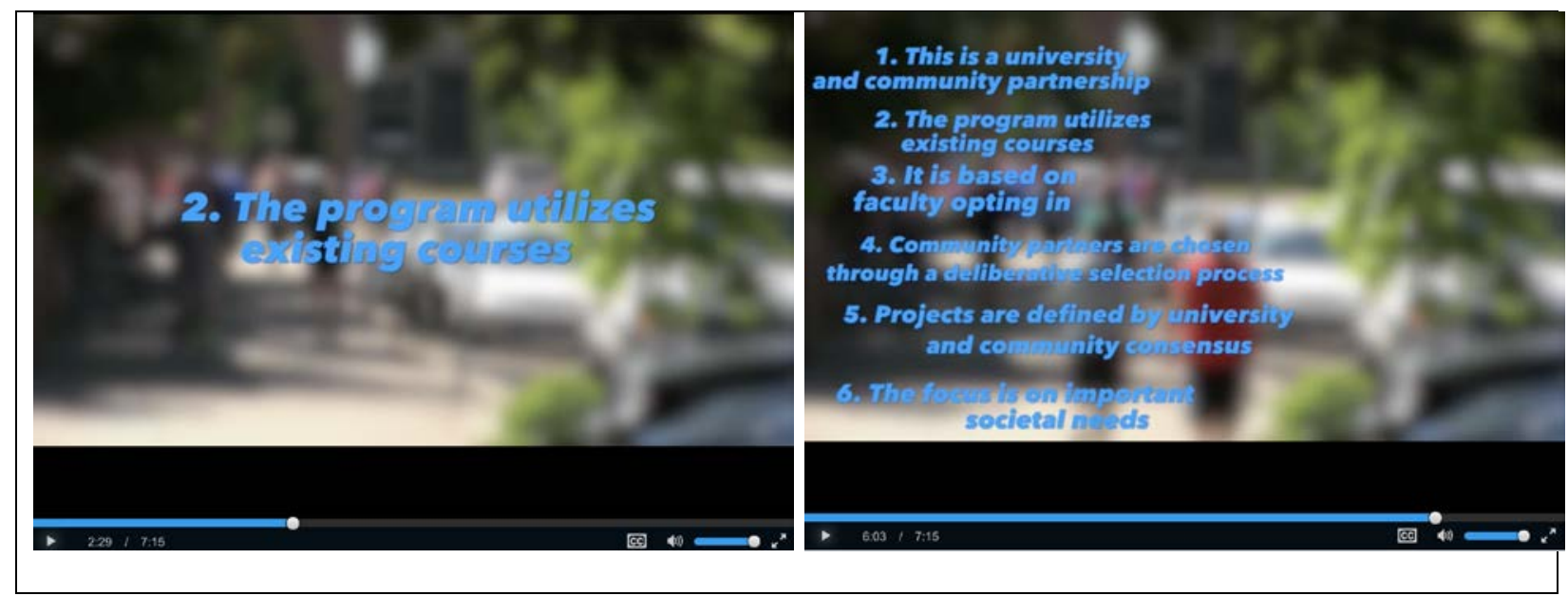

Figure 7: Screenshots from the 12 Key Tenets video. 



\subsection{CONCLUSION}

Overall, this NITC-funded project helped empower universities to improve undergraduate and graduate transportation and sustainability education while simultaneously providing tangible benefits to city livability, safety and environmental sustainability across the country. It continues to be clear that communities across the U.S. have transportation needs that would benefit from targeted university engagement. The SCYP model, which emphasizes community-initiated, community-driven, and jointly community-led projects remains greatly needed. Transportation issues are vexing and challenging, and cities have much to gain from utilizing the creative, cutting-edge ideas of students and faculty from across the academic academy through the SCYP model.

This NITC project helped expand the number of institutions putting the SCYP model into practice. Since this NITC grant started, several universities are now moving forward with their implementation of the SCYP model. The University of South Florida, the University of Colorado, Denver, and Western Washington University have all launched with specific technical assistance provided through this NITC grant. Indirectly, the development of other support material through this grant has helped other programs launch or prepare to launch next academic year.

Importantly, the training resources created through this grant will provide a lasting support system for transportation-focused universities seeking to launch SCYP-based programs. Going forward, a university interested in adopting the model will be able to visit the SCI website and access detailed information about transportation-oriented projects that they can replicate at their university. These schools will also be able to access introductory videos to share with administrators and cities, as well as webinars and podcasts that will help them begin to formulate the logistical details of launching the model within their context. In addition, the new online training content will support model dissemination into the future. While SCI has historically had limited resources to visit and train universities, these training modules have made it possible to transfer information about SCYP around the world, without the need for an SCI director to be present.

There are a variety of recommendations and potential next steps for expanding the impact of this project. Video profiles of classes could be created to serve as a pedagogical resource for professors interested in replicating transportation coursework. State DOTs could become more actively involved in SCYP projects, and could provide more mechanisms for executing projects. Finally, USDOT could broaden its perspective of transportation education. By getting beyond academic silos, USDOT could engage and utilize a wider variety of educational initiatives to help address our city's greatest transportation challenges. Helping to seed new university programs and provide technical assistance during start-up phases would be worthwhile investments that would yield years of impact and could significantly transform the nextgeneration transportation workforce. 



\section{REFERENCES}

Barry Checkoway, "Reinventing the Research University for Public Service," Journal of Planning Literature 11 (1997): 307-12.

Zenia Kotval,"Teaching Experiential Learning in the Urban Planning Curriculum," Journal of Geography in Higher Education 27 (2003): 297-308.

Asha Weinstein Agrawal and Jennifer Dill, "To Be a Transportation Engineer or Not? How Civil Engineering Students Choose a Specialization," Transportation Research Record no. 2046 (2008): 9. 
Transportation Research and Education Center

Portland State University

1900 S.W. Fourth Ave., Suite 175

Portland, OR 97201 